\title{
Water quality investigation in the Hawkesbury-Nepean River in Sydney using Principal Component Analysis
}

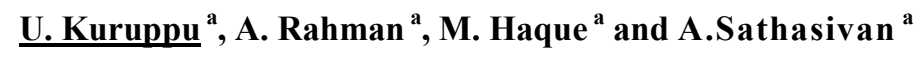 \\ ${ }^{a}$ School of Computing, Engineering and Mathematics, University of Western Sydney, Australia \\ E-mail: u.kuruppu@uws.edu.au
}

\begin{abstract}
The Hawkesbury-Nepean River System (HNRS) is an icon of Australia's largest city Sydney. Although there are a number of dams and in-stream structures throughout the river system, the HNRS is considered to be an unregulated river. Since European settlement, the HNRS has been used as a primary water source to meet the drinking water needs for over $80 \%$ of Sydney's population. The fact that it is located in the peri-urban areas dictates that it receive pollutants from a number of sewage treatment plants, located within the catchment, and the storm water runoff from agricultural and urban lands. Sydney Catchment Authority regularly monitors the water quality of the HNRS which generates a large three dimensional (different sampling stations and different parameters over time) data set containing useful information on pollutant build up and washoff on/from this river system.

In this study, factor analysis was used to identify the most significant water quality monitoring station(s). It was found that the three principal components explained more than $90 \%$ of the total variance in the data set. Moreover, this study showed that the dimensionality of the water quality parameters can be reduced to eight principal components which explained more than $70 \%$ of the total variance. Information obtained in this study can be used to design an optimal sampling strategy, which could reduce the number of sampling stations in the river system. However, further study is needed to confirm this initial finding.
\end{abstract}

Keywords: Hawkesbury-Nepean River, principal component analysis, factor analysis, water quality 
Kuruppu et al., Water quality investigation in the Hawkesbury-Nepean River in Sydney using Principal Component Analysis

\section{INTRODUCTION}

Hawkesbury-Nepean River System (HNRS, shown in Figure 1) is the main source of fresh drinking water supply to more than 4.8 million people living in and around Sydney. The HNRS system is a combination of two major rivers (Figure 1), the Nepean River $(155 \mathrm{~km})$ and the Hawkesbury River (145 km) (Markich and Brown, 1998). The river system is complex in nature, the upper part contains poorly accessible gorges, the middle part is running through irrigated farm lands and the lower part has tidal slopes with deposited soil pockets (Diamond, 2004). The middle part of the river is being continuously influenced by increasing population growth, urbanization, industrialization and other human activities which cause contamination of the quality of the river water from different sources (e.g. sewage, stormwater, runoff from disused mines, toxic forms of blue-green algae, and waste from domestic and native animals). Pinto and Maheshwari (2011) have shown that river health in peri-urban landscapes is prone to higher degrees of degradation. Within the HNR catchment, vegetation clearance has been continuously practised over the last 200 years causing increased subsurface and agricultural runoff and sediment

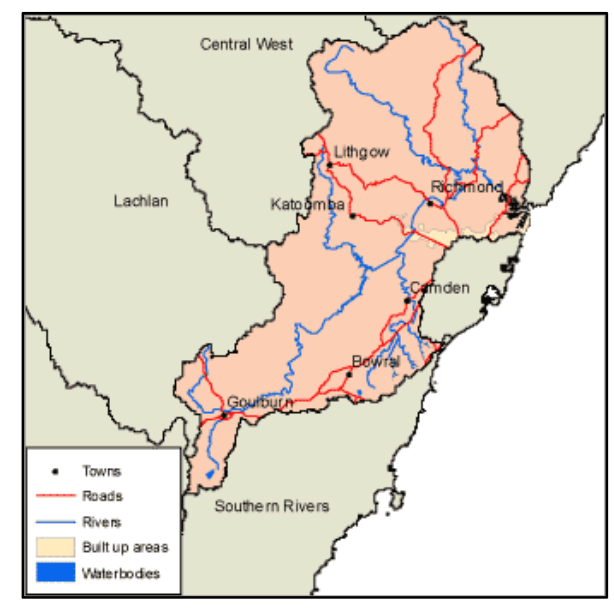

Figure 1. Hawkesbury-Nepean River System (CFOC, 2013) loads into the river system (Thomas et al. 2000). Land use in the HNR catchment includes regions that are heavily peri-urbanised and industrialised and which are important for recreational and agricultural activities and tourism (Baginska et al. 2003). Agricultural runoff contributes approximately $40 \%$ to $50 \%$ of phosphorus loads and $25 \%$ of nitrate loads into the HNRS which are believed to have originated from agricultural and animal farms (Markich and Brown 1998).

A regular water quality monitoring program generates reliable data which reflect the state of the water quality of a river. However, generating good data is not enough to meet the objectives of a water quality monitoring program. Data must be processed and presented in a manner that provides the understanding of the spatial and temporal patterns in water quality parameters. The intent is to use the collected set of data to explain the current state of the water more widely and make the necessary controls to overcome future water quality issues. One of the problems with many sets of multivariate data generated from a monitoring program is that there are too many variables to analyse and then to draw meaningful conclusion from this.

The multidimensionality (i.e. different sampling stations and different parameters over time) of data make analysis more complicated. Principal component analysis (PCA) and factor analysis (FA) are the two multivariate techniques with the central aim of reducing as much as possible of the laity of a multivariate data set while retaining their variation/useful information as much as possible. This objective is achieved by transforming the original variables to a new set of hypothetical variables called principal components or factors $(\mathrm{PC} / \mathrm{F})$ that are uncorrelated. They are obtained as a linear combination of the original variables. Principal components or factors explain the original variance in a monotonically decreasing way (Kovans et al., 2012). Factor analysis is similar to principal component analysis, but the two are not identical. In FA, components extracted from PCA are rotated according to a mathematically established rule (i.e., varimax, equamax and quarimax) yielding easily interpretable new variables, called varifactors (VFs) (Pinto et al 2013). FA use regression modeling techniques to test hypotheses producing error terms, while PCA is a descriptive statistical technique (Bartholomew et al., 2008). The difference between PCs obtained in PCA and VFs obtained in FA is that PCs are linear combinations of observable water quality parameters but VF are unobservable, hypothetical and latent variables (Alberto et al. 2001).

The differences between PCA and FA are further illustrated by Suhr (2009) as follows:

- PCA results in principal components that account for a maximal amount of variance for observed variables. FA account for common variance in the data. PCA inserts ones on the diagonals of the correlation matrix. FA adjusts the diagonals of the correlation matrix with the unique factors. 
Kuruppu et al., Water quality investigation in the Hawkesbury-Nepean River in Sydney using Principal Component Analysis

- PCA minimizes the sum of squared perpendicular distance to the component axis. FA estimates factors which influence responses on observed variables.

- The component scores in PCA represent a linear combination of the observed variables weighted by eigenvectors. The observed variables in FA are linear combinations of the underlying and unique factors.

In this study, PCA and FA both were applied to find out the most significant water quality monitoring stations in the HNRS. In addition, PCA was applied to find out the most significant water quality parameters in the HNRS. The StatistiXL software package was employed for the data analysis.

\section{STUDY AREA AND DATA}

In this study, a total 28 physical, chemical and biological water quality parameters were considered in PCA and FA. These parameters were measured fortnightly by Sydney Catchment Authority at 15 different water quality monitoring stations of the HNRS. Descriptions and locations of water quality monitoring stations are presented in Table 1 and Figure 2, respectively. The descriptive statistics of the water quality parameters are presented in Table 2.

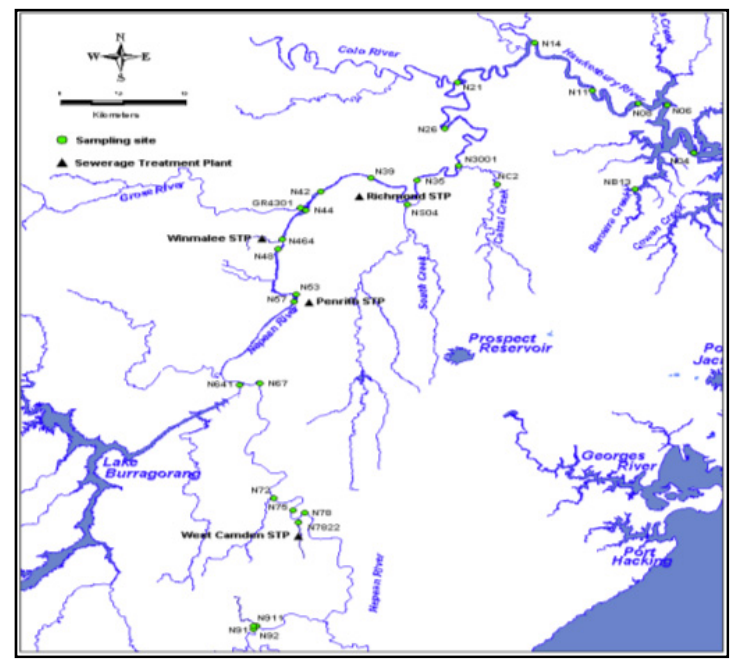

Figure 2. Map of water quality monitoring stations along Hawkesbury-Nepean River System (SCA, 2001)

Table 1. Water quality monitoring stations

\begin{tabular}{|l|l|}
\hline Site code & Site \\
\hline E851 & Shoalhaven River downstream of Tallowa Dam \\
\hline N14 & Hawkesbury River at Wisemans Ferry downstream of Car Ferry \\
\hline N21 & Hawkesbury River at Lower Portland upstream of Colo River \\
\hline N35 & Hawkesbury River at Wilberforce upstream of Cattai Creek \\
\hline N42 & Hawkesbury River at North Richmond upstream of North Richmond Water Treatments Works \\
\hline N44 & Nepean River at Yarramundi Bridge upstream of Grose River \\
\hline N57 & Nepean River at Penrith Weir upstream of Boundary Creek and Penrith Sewage Treatment Plant \\
\hline N64 & Nepean River 500m downstream of confluence of Warra river \\
\hline N641 & Warragamba River (North Basin) downstream of Warragamba STP \\
\hline N67 & Nepean River at Wallacia Bridge upstream of Warragamba River \\
\hline N75 & Nepean River at Sharpes Weir downstream of Matahil Creek and Camden Sewage Treatment Plant \\
\hline N85 & Nepean River at Menangle Bridge \\
\hline N86 & Nepean River at Pheasants Nest \\
\hline N881 & Nepean River at downstream of Broughtons pass Weir \\
\hline N92 & Nepean River at Maldon Weir upstream of Stonequarry Creek and Picton Sewage Treatment Plant \\
\hline
\end{tabular}


Kuruppu et al., Water quality investigation in the Hawkesbury-Nepean River in Sydney using Principal Component Analysis

Table 2. Descriptive statistics and abbreviations of the data set

\begin{tabular}{|c|c|c|c|c|c|c|}
\hline Water quality Parameter & Abbreviation & Units & Min & Max & Median & No. of data values \\
\hline $\mathrm{pH}$ & $\mathrm{PH}$ & & 5.78 & 9.94 & 7.63 & 1666 \\
\hline Lorenzen & LOR & $\mathrm{ug} / \mathrm{L}$ & 0.10 & 539.90 & 4.40 & 1666 \\
\hline Iron Total & TI & $\mathrm{mg} / \mathrm{L}$ & 0.04 & 5.62 & 0.29 & 1666 \\
\hline Nitrogen TKN & TKN & $\mathrm{mg} / \mathrm{L}$ & 0.02 & 5.40 & 0.27 & 1666 \\
\hline Temperature & TEMP & Deg C & 8.10 & 30.60 & 19.50 & 1666 \\
\hline Chlorophyll-a & CHLA & $\mathrm{ug} / \mathrm{L}$ & 0.20 & 253.10 & 5.10 & 1666 \\
\hline Iron Filtered & FI & $\mathrm{mg} / \mathrm{L}$ & 0.01 & 3.43 & 0.09 & 1666 \\
\hline True Colour & TCOL & & 1.00 & 93.00 & 11.00 & 1666 \\
\hline Nitrogen Total & $\mathrm{TN}$ & $\mathrm{mg} / \mathrm{L}$ & 0.08 & 5.90 & 0.45 & 1666 \\
\hline Turbidity & TUR & NTU & -0.60 & 380.00 & 3.85 & 1666 \\
\hline Alkalinity & ALK & $\mathrm{mgCaCO} 3 / \mathrm{L}$ & 1.00 & 298.00 & 40.00 & 1666 \\
\hline Aluminium Total & TA & $\mathrm{mg} / \mathrm{L}$ & 0.01 & 3.97 & 0.08 & 1666 \\
\hline Phosphorus Total & TP & $\mathrm{mg} / \mathrm{L}$ & 0.01 & 0.18 & 0.01 & 1666 \\
\hline Suspended Solids & SS & $\mathrm{mg} / \mathrm{L}$ & 1.00 & 105.00 & 3.00 & 1666 \\
\hline Nitrogen Oxidised & $\mathrm{NO}$ & $\mathrm{mg} / \mathrm{L}$ & 0.00 & 5.00 & 0.17 & 1666 \\
\hline Aluminium Filtered & FA & $\mathrm{mg} / \mathrm{L}$ & 0.00 & 0.45 & 0.01 & 1666 \\
\hline Manganese Filtered & FM & $\mathrm{mg} / \mathrm{L}$ & 0.00 & 0.35 & 0.01 & 1666 \\
\hline Conductivity Field & EC & $\mathrm{mS} / \mathrm{cm}$ & 0.01 & 48.40 & 0.30 & 1666 \\
\hline Nitrogen Ammonical & NH-N & $\mathrm{mg} / \mathrm{L}$ & 0.01 & 0.41 & 0.01 & 1666 \\
\hline Phosphorus Filterable & FP & $\mathrm{mg} / \mathrm{L}$ & 0.00 & 0.11 & 0.01 & 1666 \\
\hline Silicate Reactive & $\mathrm{RS}$ & $\mathrm{SiO} 2 \mathrm{mg} / \mathrm{L}$ & 0.01 & 14.90 & 1.71 & 1666 \\
\hline Dissolved Organic Carbon & DOC & $\mathrm{mg} / \mathrm{L}$ & 0.20 & 350.00 & 4.60 & 1666 \\
\hline UV Absorbing constituents & UV & & 0.01 & 0.93 & 0.12 & 1666 \\
\hline
\end{tabular}

\section{METHODOLOGY}

In this study, PCA was performed first to identify the most important water quality monitoring station(s) in the HNRS. For the purpose of this analysis, the median value of each parameter was used as the median is better suited for a skewed distribution to describe the central tendency of the data. In this analysis, stations with correlation coefficient greater than 0.9 , were taken as principal water quality monitoring stations. Equations for principal components were derived by considering the loadings of the variables (water quality monitoring stations).

To further identify the monitoring stations that are important in revealing surface water quality variations, a FA was employed. Varimax rotation was selected as the data rotation method, as it makes an orthogonal rotation of the factor axes to maximize the variance of the squared loadings of a factor on all the variables in a factor matrix which has the effect of differentiating the original variables by extracted factor. Each factor has either large or small loadings of any particular variable. A varimax solution was used to identify each variable with a single factor. This is the most common rotation option used in the PCA and PF analysis. However, the orthogonality (i.e., independence) of factors is often an unrealistic assumption (Russell, 2002). In the second step, PCA was performed on water quality data to identify the principal components that explain the most of the variance in the water quality data set.

\section{RESULTS AND DISCUSSION}

When 15 monitoring stations were reduced to three principal components, it explained $95.2 \%$ of the total variance and the rest of the 12 components only accounted for Table 3. Principal components with eigenvalues $>1$

\begin{tabular}{|l|r|r|r|}
\hline \multicolumn{1}{|c|}{ Value } & PC 1 & \multicolumn{1}{c|}{ PC 2 } & \multicolumn{1}{c|}{ PC 3 } \\
\hline Eigenvalue & 11.96 & 1.328 & 0.993 \\
\hline Percentage of Variance & 79.731 & 8.855 & 6.62 \\
\hline Cumulative Percentage & 79.731 & 88.586 & 95.206 \\
\hline
\end{tabular}
$4.8 \%$ (Table 3). Further, the first, second and third components accounted for about $79.6 \%, 8.8 \%$ and $6.6 \%$ of the total variance in the data set, respectively. Therefore the discussion is focused only on the first three principal components. 
Kuruppu et al., Water quality investigation in the Hawkesbury-Nepean River in Sydney using Principal Component Analysis

Table 4. Component score coefficients for first three PCs (for monitoring stations)

\begin{tabular}{|l|l|l|l|}
\hline Variable & PC 1 & PC 2 & PC 3 \\
\hline E851 & 0.218 & 0.316 & -0.386 \\
\hline N14 & 0.265 & -0.221 & -0.176 \\
\hline N21 & 0.243 & -0.116 & -0.338 \\
\hline N35 & 0.272 & -0.081 & 0.098 \\
\hline N42 & 0.287 & 0.09 & 0.03 \\
\hline N44 & 0.249 & 0.094 & 0.489 \\
\hline N57 & 0.229 & 0.145 & 0.572 \\
\hline N64 & 0.279 & -0.106 & -0.197 \\
\hline N641 & 0.284 & -0.031 & -0.061 \\
\hline N67 & 0.278 & -0.17 & 0.15 \\
\hline N75 & 0.274 & -0.261 & 0.022 \\
\hline N85 & 0.284 & -0.073 & 0.076 \\
\hline N86 & 0.234 & 0.489 & 0.006 \\
\hline N881 & 0.21 & 0.547 & -0.207 \\
\hline N92 & 0.251 & -0.374 & -0.119 \\
\hline
\end{tabular}

Table 5 demonstrates the rotated factor correlation coefficient (obtained from FA) for 15 water quality monitoring stations. In this study, the factor correlation coefficient was considered to be significant if the value was greater than 0.7 . This conservative criterion was selected because the study area was large and the river system was deemed to be highly non-linear and dynamic. From Table 5 water quality monitoring stations N14, N64, N641, N67, N75, N85, N86, N881, N92, N57 and $\mathrm{N} 21$ have coefficient values greater than 0.70 , and hence these are considered to be the most important water quality monitoring stations.
The first component had almost equal loadings on all variables (Table 4) and therefore was a measure of overall performance of the stations and also it showed an extremely high correlation with the measured data. It accounted for $79.7 \%$ of the data variance (Table 3 ). Similarly, the second and third components had different loadings on different variables. Hence, PC2 and PC3 represented a difference among the stations. Loading reflected only the relative importance of a variable within a component, and did not reflect the importance of the component itself (Davis, 1986).

The results of the first PCA identified three important components that accounted for $95.2 \%$ of the variance in the dataset.

Table 5. Varimax rotated factor loadings for first 5 factors

\begin{tabular}{|l|l|l|l|l|l|}
\hline Variable & $\begin{array}{l}\text { Factor } \\
1\end{array}$ & $\begin{array}{l}\text { Factor } \\
2\end{array}$ & $\begin{array}{l}\text { Factor } \\
3\end{array}$ & $\begin{array}{l}\text { Factor } \\
4\end{array}$ & $\begin{array}{l}\text { Factor } \\
5\end{array}$ \\
\hline E851 & 0.378 & 0.672 & 0.125 & -0.19 & 0.594 \\
\hline N14 & $\mathbf{0 . 7 6 6}$ & 0.265 & 0.27 & -0.452 & 0.081 \\
\hline N21 & 0.582 & 0.339 & 0.147 & $-\mathbf{0 . 7 1 7}$ & 0.098 \\
\hline N35 & 0.555 & 0.267 & 0.566 & -0.524 & 0.118 \\
\hline N42 & 0.621 & 0.536 & 0.498 & -0.266 & 0.07 \\
\hline N44 & 0.404 & 0.303 & 0.85 & -0.128 & 0.058 \\
\hline N57 & 0.293 & 0.288 & $\mathbf{0 . 9 0 4}$ & -0.099 & 0.033 \\
\hline N64 & $\mathbf{0 . 8 1 8}$ & 0.432 & 0.248 & -0.27 & 0.094 \\
\hline N641 & $\mathbf{0 . 7 6 8}$ & 0.473 & 0.373 & -0.185 & 0.07 \\
\hline N67 & $\mathbf{0 . 7 7 6}$ & 0.244 & 0.537 & -0.174 & 0.082 \\
\hline N75 & $\mathbf{0 . 8 4 2}$ & 0.189 & 0.424 & -0.244 & 0.116 \\
\hline N85 & $\mathbf{0 . 7 4 9}$ & 0.368 & 0.498 & -0.175 & 0.11 \\
\hline N86 & 0.261 & $\mathbf{0 . 8 4 6}$ & 0.43 & -0.12 & 0.037 \\
\hline N881 & 0.195 & $\mathbf{0 . 9 2 6}$ & 0.238 & -0.184 & 0.074 \\
\hline N92 & $\mathbf{0 . 9 4 6}$ & 0.119 & 0.227 & -0.16 & 0.111 \\
\hline & & & & \\
\hline
\end{tabular}

PCA for the water quality parameters dataset developed eight principal components with eigenvalues $>1$ explaining about $72.7 \%$ of the total variance in the data set. The first PC accounts for $24.1 \%$ of the total variance which was highly correlated (loading $>0.7$ ) with total iron $(\mathrm{TI})$, true color (TCOL), turbidity, aluminum total, and UV absorbent. Whereas, the other seven PCs, although accounted for $12.7 \%, 8.3 \%$, $7.3 \%, 6.6 \%, 5.2 \%, 4.4 \%$ and $3.8 \%$, respectively, correlated (loading $>0.7$ ) with none of the parameters (Table 6 and Table 7).

Principal components extracted for water quality parameters did not have a strong correlation when comparing with principal components extracted for water quality monitoring stations. Monitoring stations are primarily controlled by hydrological conditions, while water quality parameters are controlled by a combination of hydrological, chemical, physical and biological conditions, so it is expected that the monitoring stations would have higher correlation than the water quality parameters.

Table 6. Explained variance and eigenvalues (for water parameters)

\begin{tabular}{|l|l|l|l|l|l|l|l|l|}
\hline Value & PC 1 & PC 2 & PC 3 & PC 4 & PC 5 & PC 6 & PC 7 & PC 8 \\
\hline Eigenvalue & 6.756 & 3.559 & 2.343 & 2.067 & 1.851 & 1.460 & 1.243 & 1.073 \\
\hline Percentage of variance & 24.130 & 12.712 & 8.366 & 7.383 & 6.612 & 5.215 & 4.441 & 3.832 \\
\hline Cumulative percentage & 24.130 & 36.842 & 45.209 & 52.591 & 59.203 & 64.419 & 68.859 & 72.691 \\
\hline
\end{tabular}


Kuruppu et al., Water quality investigation in the Hawkesbury-Nepean River in Sydney using Principal Component Analysis

Table 7. Component loadings for first eight PCs (water quality parameters)

\begin{tabular}{|c|c|c|c|c|c|c|c|c|}
\hline Variable & PC 1 & PC 2 & PC 3 & PC 4 & PC 5 & PC 6 & PC 7 & PC 8 \\
\hline $\mathrm{PH}$ & -0.404 & 0.450 & -0.092 & 0.065 & -0.148 & -0.036 & 0.351 & -0.464 \\
\hline LOR & 0.052 & 0.402 & 0.080 & -0.599 & 0.517 & 0.092 & 0.207 & -0.112 \\
\hline TI & 0.907 & -0.133 & 0.080 & -0.078 & -0.007 & 0.179 & -0.016 & -0.030 \\
\hline TKN & 0.322 & 0.515 & -0.239 & -0.102 & -0.038 & -0.218 & 0.081 & 0.042 \\
\hline TEMP & 0.059 & 0.168 & 0.487 & -0.315 & -0.260 & -0.629 & 0.089 & 0.019 \\
\hline CHLA & 0.085 & 0.507 & 0.080 & -0.630 & 0.502 & 0.089 & 0.141 & -0.059 \\
\hline FI & 0.504 & -0.554 & -0.220 & -0.236 & -0.011 & 0.050 & 0.059 & -0.161 \\
\hline TCOL & 0.754 & -0.342 & -0.207 & -0.016 & 0.195 & -0.296 & 0.061 & -0.134 \\
\hline $\mathrm{TN}$ & 0.172 & 0.618 & -0.665 & -0.017 & -0.110 & -0.063 & -0.073 & 0.250 \\
\hline TUR & 0.748 & 0.294 & 0.288 & 0.203 & 0.013 & 0.205 & 0.101 & 0.055 \\
\hline ALK & -0.236 & 0.482 & -0.157 & -0.003 & -0.424 & -0.122 & 0.143 & -0.448 \\
\hline TA & 0.802 & 0.220 & 0.170 & 0.272 & 0.138 & 0.052 & -0.080 & -0.064 \\
\hline $\mathrm{TP}$ & 0.700 & 0.428 & 0.063 & 0.107 & 0.066 & -0.025 & -0.166 & -0.087 \\
\hline SS & 0.605 & 0.409 & 0.361 & 0.033 & 0.076 & 0.220 & -0.295 & -0.069 \\
\hline $\mathrm{NO}$ & 0.061 & 0.510 & -0.694 & 0.026 & -0.117 & 0.022 & -0.123 & 0.283 \\
\hline FA & 0.487 & -0.288 & -0.198 & 0.208 & 0.332 & -0.232 & 0.008 & -0.254 \\
\hline FM & 0.486 & -0.430 & -0.171 & -0.415 & -0.405 & 0.287 & 0.096 & -0.027 \\
\hline $\mathrm{EC}$ & -0.046 & 0.116 & 0.305 & 0.046 & -0.127 & 0.193 & -0.554 & -0.219 \\
\hline NH-N & 0.498 & -0.038 & -0.345 & -0.222 & -0.477 & 0.044 & -0.059 & -0.144 \\
\hline FP & 0.527 & 0.395 & -0.082 & 0.275 & -0.110 & -0.132 & -0.213 & -0.259 \\
\hline $\mathrm{RS}$ & 0.570 & -0.352 & -0.272 & 0.106 & 0.165 & -0.202 & -0.033 & 0.079 \\
\hline DOC & 0.117 & 0.039 & -0.041 & -0.014 & 0.092 & -0.170 & 0.004 & 0.266 \\
\hline UV & 0.742 & -0.155 & -0.122 & 0.010 & 0.211 & -0.303 & 0.096 & -0.036 \\
\hline
\end{tabular}

\section{CONCLUSION}

Water-quality monitoring programs generate complex multidimensional data. Multivariate statistical techniques can be used to extract useful information from this data. In this case study, factor analysis was performed to identify the most significant water quality monitoring stations in the Hawkesbury-Nepean River System. The stations N14, N64, N641, N67, N75, N85, N86, N881, N92, N57 and N21were found to be the most significant sampling sites explaining the most variation in the water quality data in the HawkesburyNepean River System. This result might be used to reduce the number of sampling sites in the river system. Principal component analysis allowed deriving three principal components which explained more than $90 \%$ of the total variance in data set. The findings of this preliminary data analysis need further confirmation by a more in-depth analysis, which is being undertaken.

\section{ACKNOWLEDGEMENTS}

The authors would like to thank Sydney Catchment Authority, New South Wales, Australia for providing water quality data used in this study.

\section{REFERENCES}

Alberto,W., Diaz,M.P., Ame,M.V., Pesce,S.B., Hued,A.C., and Bistoni,M.A. (2001). Pattern recognition techniques for the evaluation of spatial and temporal variations in water quality. A Case Study: Suqu a River Basin (Córdoba-Argentina). Water Research, 35, 2881-2894.

Baginska,B., Pritchard,T., and Krogh,M. (2003). Roles of land use resolution and unit-area load rates in assessment of diffuse nutrient emissions. Journal of Environmental Management, 69, 39-46.

Bartholomew, D.J., Steele, F., Galbraith, J., and Moustaki, I. (2008). Analysis of Multivariate Social Science Data. Statistics in the Social and Behavioral Sciences Series (2nd ed.)

CFOC (2013). Caring for our Country, accessed on http://www.nrm.gov.au/about/nrm/regions/nswhnep.html

Davis, J.C. (1986). Statistical and data analysis in geology, second ed. John Wiley \& Sons, New York. 
Kuruppu et al., Water quality investigation in the Hawkesbury-Nepean River in Sydney using Principal Component Analysis

Diamond, R. (2004).Water andSydney'sFutureeBalancing theValue of Our Rivers and Economy. Final Report of the Hawkesbury- Nepean River Management Forum. NSW, Department of Infrastructure, Planning and Natural Resources, Sydney.

Jackson, J.E. (1991). A User's Guide to Principal Components. John Wiley \& Sons, New York.

Kovacs, J., Tanos, P., Korponai, J., Szekely, I.K., Gonda, K., Soregi, K.J., Hatvani, I.G. (2012). Analysis of Water Quality Data for Scientists. Water Quality Monitoring and Assessment (Chapter3)

Markich, S.J., and Brown, P.L. (1998). Relative importance of natural and anthropogenic influences on the fresh surface water chemistry of the Hawkesbury-Nepean River, southeastern Australia. Science of the Total Environment, 217, 201-230.

Pinto, U., Maheshwari, B.L., Ollerton, R.L. (2013). Analysis of long-term water quality for effective river health monitoring in peri-urban landscapes - a case study of the Hawkesbury-Nepean river system in NSW, Australia. Enviromental Monitoring and Assessment, June 2013.

Pinto, U., Maheshwari, B.L. (2011), River health assessment in peri-urban landscapes: An application of multivariate analysis to identify the key variables, Water Research, 45, 3915 -3924

Russell, D.W. (2002). In search of underlying dimensions: The use (and abuse) of factor analysis in Personality and Social Psychology Bulletin. Personality and Social Psychology Bulletin, 28 (12): 162946.

SCA (2001). Annual water quality monitoring report. Sydney Catchment Authority, 2000-2001.

Suhr, D. (2009). Principal component analysis vs. exploratory factor analysis. SUGI 30 Proceedings. Retrieved 5 April 2012.

Thomas, M., Parker, C., and Simons, M. (2000). The dispersal and storage of trace metals in the Hawkesbury River valley. S. Brizga and B. Finlayson (Eds.), River management: the Australasian experience (pp. 197219). Sydney: John Wiley and Sons. 